\title{
Problems with implementing guidelines: a randomised controlled trial of consensus management of dyspepsia
}

\author{
Roger H Jones, Susan Lydeard, Joan Dunleavey
}

\begin{abstract}
Objective-To determine the feasibility and benefit of developing guidelines for managing dyspepsia by consensus between general practitioners (GPs) and specialists and to evaluate their introduction on GPs' prescribing, use of investigations, and referrals.

Design-Randomised controlled trial of effect of consensus guidelines agreed between GPs and specialists on GPs' behaviour.

Setting-Southampton and South West Hampshire Health District, United Kingdom.
\end{abstract}

Subjects-179 GPs working in 45 practices in Southampton district out of 254 eligible GPs, 107 in the control group and 78 in the study group.

Main measures-Rates of referral and investigation and costs of prescribing for dyspepsia in the six months before and after introduction of the guidelines.

Results-Consensus guidelines were produced relatively easily. After their introduction referral rates for upper gastrointestinal symptoms fell signifcantly in both study and control groups, but no significant change occurred in either group in the use of endoscopy or radiology, either in terms of referral rates, patient selection, or findings on investigation. No difference was observed between the control and study group in the number of items prescribed, but prescribing costs rose by $25 \%$ (from $£ 2634$ to $£ 3215$ per GP) in the study group, almost entirely due to an increased rate of prescription of ulcer-healing agents.

Department of Primary Medical Care, University of Southampton, Southampton SO1 6ST

Roger Jones, senior lecturer in primary medical care Susan Lydeard, research assistant Joan Dunleavey, research assistant

Correspondence to: Professor R H Jones, Department of General Practice, UMDS (Guy's and St Thomas's Hospitals), 80 Kennington Road, London SE11 6SP

Accepted for publication 22 October 1993 practice, against which current activity can be measured and to which this activity aspires. ${ }^{1}$
These criteria may take the form of a management protocol, representing a consensus statement or set of guidelines which attempt to specify the optimum management of a given medical condition. Smith observed that there is no agreement on who should write these guidelines or how they should be used ${ }^{2}$ but pointed to evidence that clinicians are more likely to follow guidelines if they have played a part in creating them. ${ }^{34}$ On the other hand, time and resources will be wasted in reinventing guidelines for common conditions. One compromise might be the modification of nationally agreed guidelines by local clinicians, who would retain an essential feeling of ownership. The importance of precision, specificity, and efficacy as characteristics of clinical guidelines has been emphasised, but research is now needed to assess the impact of guidelines on clinical practice. ${ }^{56}$

Dyspepsia is an important, common condition which has been the subject of vigorous debate over recent years. ${ }^{7-9}$ The population prevalence of dyspepsia is about $40 \%$, and a quarter of dyspeptic patients consult general practitioners (GPs)..$^{11}{ }^{11}$ There are wide variations in the management of dyspepsia, in terms of investigation, referral, and prescribing. Local agreement on standards of practice might be expected to lead to more appropriate use of resources and improved health outcomes for patients. The recommendations of an international working party have been used by many clinicians as a basis for management for some time, ${ }^{12}$ although primary care physicians were not involved in producing them. In this study we used published information about the management of dyspepsia as the basis for producing management guidelines, agreed by consensus between GPs and specialists, and evaluated the effect of introducing them on prescribing, investigations, and referral for dyspepsia in a randomised controlled trial.

\section{Methods}

The study was carried out in the Southampton and South West Hampshire Health District, which has a population of about 500000 and in which 254 GPs work in 64 practices. The district is served by two central hospitals in the city of Southampton and a small community hospital at Lymington, in the New Forest. The study was designed as a randomised controlled trial to assess the effect of guidelines on GPs' behaviour in managing dyspepsia. These 
guidelines were drawn up by consensus between the study group of GPs and hospital specialists. Information about referral, investigations, and prescribing for upper gastrointestinal symptoms was collected for six months before and after development and introduction of the guidelines.

\section{STUDY PRACTICES}

We collected information about all the practices in the district regarding their involvement in undergraduate teaching, continuing medical education, research, and their readiness to adopt new and innovative ideas - for example, clinics led by nurses. A composite score reflecting these variables was used to stratify the practices, together with size of partnership, type of premises, and geographical location. Within these subgroups practices were numerically coded and randomised to control and study groups with tables of random numbers.

\section{CONSENSUS MEETINGS}

Consensus meetings were a central feature of the study design. Two meetings, about two months apart, were planned for each of three geographical divisions of the health district in order to maximise each GP's opportunity to attend. All three of the first and second sets of meetings had the same agenda. All general practices in the study group were invited to attend whichever meeting was most convenient, and consultant surgeons, physicians, and radiologists were also invited and given the same freedom of choice. A timetable of meetings was drawn up to ensure that a representative from each specialty attended every meeting. All attendees received an outline of the study design and a statement of the purpose of meetings before attendance, accompanied by a selection of reprints of papers on managing dyspepsia, including the report of the international working party.

The management of dyspepsia was considered in relation to the choice and timing of investigations, decisions to refer for specialist advice and management, including prescribing. In addition, other diagnostic problems in primary care relating to dyspepsia were included in the agenda.

The main points from the first round of three meetings were collected into draft guidelines and circulated for comment to all GPs in the study group and participating specialists before the second round of meetings in the same geographical areas. All of these GPs were again invited to attend, together with a consultant radiologist, surgeon, and physician. Definitive guidelines agreed by all three local meetings were published after the second meeting and circulated to all GPs in the study group.

The guidelines consisted of a six page document, supported by five reprints of key references and three quick reference laminated cards dealing with decisions to investigate or refer, choice of investigation, and positive diagnosis of irritable bowel syndrome. The box summarises the main points of the

\section{Management guidelines for dyspepsia:} summary

- Early investigation of patients aged over 50 with new symptoms and all patients with "alarm symptoms"

- Deferred investigation of patients aged under 50 without alarm symptoms

- Empirical use of therapeutic course(s) of ulcer-healing drugs often appropriate

- Endoscopy preferable to radiology for most patients

- Positive diagnosis of irritable bowel syndrome important

- Consider costs of investigation and prescribing

guidelines. Adherence to the guidelines would have been expected to lead to an increase in use of endoscopy compared with that of barium meals, fewer investigations of younger patients, and a change in the prescribing pattern of $\mathrm{H}_{2}$-antagonists.

\section{COLLECTION OF DATA}

$G P s$ - A postal questionnaire was used to obtain information from GPs about their willingness to participate in the study, individual size of patient list, and workload, expressed as the number of patients seen in surgery appointments each month.

Referrals - Research clerical staff were identified in the medical records departments of the Southampton hospitals to identify and copy all referral letters sent by GPs to medical and surgical outpatient departments over the six month study periods before and after the introduction of the guidelines. Referrals for upper gastrointestinal problems were identified by us and extracted for analysis.

Investigation - Systems were set up in the radiology departments of the Southampton and Lymington hospitals to identify, tag and follow up all GPs' requests for upper gastrointestinal radiography in the two study periods. Requests for upper gastrointestinal endoscopy by referral letter were also identified and followed up in the same way as referrals.

Prescribing - Quarterly prescribing analyses for all the general participating GPs were obtained, with their permission, from prescribing analysis and cost data (PACT) level 3 output provided by the Prescription Pricing Authority. Detailed information about the prescription of individual gastrointestinal drugs and their cost, by British National Formulary $^{13}$ group, was available for each doctor. PACT data relating to prescribing of gastrointestinal drugs for the second quarter of each of the two study periods were used for analysis.

\section{ANALYSIS}

Data were handled and analysed with SPSSPC software. The $\chi^{2}$ test was used to measure differences between groups; distributions of variables were tested for skewness, and logarithmic transformation was used on skewed distributions before differences 
between means were evaluated by Student's $t$ test.

\section{Results}

STUDY PRACTICES

Practices were randomised into control and study groups in about equal numbers. In all, 179 out of the 254 eligible GPs agreed to provide information about workload. The final control group therefore consisted of 24 practices, representing $101 \mathrm{GPs}$, and the study group 21 practices, representing 78 GPs. We continued to collect data about referral, prescribing, and use of investigations for all 254 GPs to ensure that the non-participants did not represent a different group from those taking part. Although information about workload was not available, we were unable to detect notable differences between participants and non-participants.

CONSENSUS MEETINGS

Consensus meetings of GPs, physicians, surgeons, and radiologists were attended by $14(18 \%)$ of the 78 eligible GPs in the study group, representing seven $(33 \%)$ of the 21 eligible study practices. Each meeting lasted for about two hours, during which a focused discussion identified areas of agreement and disagreement about the indications for investigation of dyspepsia, the choice and timing of investigations, the use of ulcerhealing agents either before or after investigation, and the importance of identifying patients with a positive diagnosis of irritable bowel syndrome. The consensus statements, which were based both on a review of published work and on considerations of locally available facilities, were reached with little difficulty, and similar recommendations were generated in all the meetings. The specialists' contributions were particularly important in delineating the relative merits of endoscopy (recommended as the best

Table 1 Referrals and requests for endoscopy before and after introduction of guidelines

\begin{tabular}{|c|c|c|c|c|c|c|}
\hline & $\begin{array}{l}\text { Control group } \\
(n=101)\end{array}$ & $\begin{array}{l}\text { Before } \\
\text { Study group } \\
(n=78)\end{array}$ & Total & $\begin{array}{l}\text { Control group } \\
(n=101)\end{array}$ & $\begin{array}{l}\text { After } \\
\text { Study group } \\
(n=78)\end{array}$ & Total \\
\hline $\begin{array}{l}\text { All medical and } \\
\text { surgical referrals }\end{array}$ & \multicolumn{5}{|c|}{4728} & 4964 \\
\hline $\begin{array}{l}\text { Total } \\
\text { Per GP }\end{array}$ & $\begin{array}{l}\text { Referrals } \\
396 \\
3.92\end{array}$ & $\begin{array}{c}\text { for upper gastr } \\
351 \\
4.50\end{array}$ & $\begin{array}{c}\text { intestinc } \\
747 \\
4 \cdot 17\end{array}$ & $\begin{array}{c}\text { symptoms } \\
288 \\
2 \cdot 85\end{array}$ & $\begin{array}{l}308 \\
3 \cdot 95\end{array}$ & $\begin{array}{l}596^{\star} \\
3 \cdot 33\end{array}$ \\
\hline $\begin{array}{l}\text { Total } \\
\text { Per GP }\end{array}$ & $\begin{array}{l}134 \\
1 \cdot 32\end{array}$ & $\begin{array}{c}\text { Requests for } \\
120 \\
1.54\end{array}$ & $\begin{array}{c}\text { ndoscop } \\
254 \\
1 \cdot 42\end{array}$ & $\begin{array}{l}143 \\
1 \cdot 42\end{array}$ & $\begin{array}{l}144 \\
1 \cdot 86\end{array}$ & $\begin{array}{l}287 \\
1 \cdot 60\end{array}$ \\
\hline
\end{tabular}

Table 2 Requests for upper gastrointestinal radiology before and after introduction of management guidelines

\begin{tabular}{|c|c|c|c|c|c|c|}
\hline & $\begin{array}{l}\text { Control group } \\
(n=101)\end{array}$ & $\begin{array}{l}\text { Before } \\
\text { Study group } \\
\quad(n=78)\end{array}$ & Total & $\begin{array}{l}\text { Control group } \\
(n=101)\end{array}$ & $\begin{array}{l}\text { After } \\
\text { Study group } \\
(n=78)\end{array}$ & Total \\
\hline $\begin{array}{l}\text { No of patients } \\
\text { No }(\%) \text { with }\end{array}$ & $\begin{array}{c}310 \\
167(54)\end{array}$ & $\begin{array}{c}280 \\
156(56)\end{array}$ & 590 & $\begin{array}{c}274 \\
142(52)\end{array}$ & $\begin{array}{c}233^{\star} \\
133(57)\end{array}$ & $507^{\star}$ \\
\hline No $(\%)$ aged & $94(30)$ & $87(31)$ & & $77(28)$ & $68(29)$ & \\
\hline $\begin{array}{l}\text { No (\%) with } \\
\text { major lesion }\end{array}$ & $60(19)$ & $55(20)$ & & $47(17)$ & $40(17)$ & \\
\hline
\end{tabular}

${ }^{\star} \mathrm{p}<0 \cdot 05$. investigation for most patients with dyspepsia) and radiology, while the whole group generated the guidelines for deciding when early investigation was required and for the empirical use of $\mathrm{H}_{2}$-antagonists. The "cut off" age of 50 years for early investigation and the recommendation to prescribe one or two courses of ulcer-healing drugs before investigation in younger patients were supported equally by the GPs and specialists.

\section{REFERRALS}

Referrals in the six months after publication and circulation of the guidelines were compared with baseline data collected in the six months previously. Although the number of referrals to medical and surgical outpatient clinics rose overall by $5 \%$ (from 4728 to 4964 ) between the two periods, a fall in referrals for upper gastrointestinal symptoms was observed in both groups $(p<0.01)$. There were 396 (3.92 per doctor) referrals in the control group and $351(4.50$ per doctor) in the study group during the baseline period, with $288(2 \cdot 85)$ and $308(3.95)$ referrals respectively in the study period; none of these differences was significant. About a third of these referrals were requests for endoscopy; although there was a slight fall in the total number of requests for endoscopy this was not significant and there was no difference between the numbers of requests in the control and study groups (table 1).

\section{INVESTIGATIONS}

Significantly fewer upper gastrointestinal barium studies were ordered in the second period; 590 requests for barium swallows and barium meals were made in the first six months and 507 in the second $(p<0.05)$. The number requested in the control and study groups was not significantly different, and there was no evidence that barium meals were being used differently after circulation of the guidelines. Similar numbers of patients aged under 50 were referred for barium studies, the proportion of normal examinations was unchanged, and the proportion of examinations in which a major upper gastrointestinal lesion was identified (peptic ulceration, ulcerative oesophagitis, or cancer) was also unchanged (table 2).

PRESCRIBING

Prescribing for gastrointestinal symptoms accounted for about $14 \%$ of total prescribing costs, and over half of all prescribing costs for upper gastrointestinal drugs were for ulcerhealing agents. A striking feature was the appreciable individual variation in baseline prescribing costs among the GPs in both study and control groups (table 3 ). There were no significant differences in the number of items prescribed or in the costs of these prescriptions and no differences between the total prescribing costs in the study or control groups $(p=0.34)$.

When baseline and follow up data on prescribing were compared no difference was found between the study and control groups in 
Table 3 Prescribing costs $(\mathcal{f})$ before introduction of management guidelines first quarter only

\begin{tabular}{lcc}
\hline & $\begin{array}{c}\text { Control group } \\
(n=101)\end{array}$ & $\begin{array}{c}\text { Study group } \\
(n=78)\end{array}$ \\
\hline Gastrointestinal drugs: & & \\
$\quad$ All & 225447 & 204654 \\
$\quad$ Ulcer healing & 143976 & 126546 \\
Upper gastrointestinal drugs: & & \\
Mean (range) cost per GP & $2232(91-4932)$ & $2624(184-7774)$ \\
\hline
\end{tabular}

Table 4 Mean (SE) prescribing costs $(£)$ per general practitioner for upper gastrointestinal drugs and ulcer healing agents before and after introduction of management guidelines

\begin{tabular}{lcccc}
\hline & \multicolumn{2}{c}{ Before } & \multicolumn{2}{c}{ After } \\
& $\begin{array}{c}\text { Control group } \\
(n=101)\end{array}$ & $\begin{array}{c}\text { Study group } \\
(n=78)\end{array}$ & $\begin{array}{c}\text { Control group } \\
(n=101)\end{array}$ & $\begin{array}{c}\text { Study group } \\
(n=78)\end{array}$ \\
\hline Upper gastrointestinal drugs & $2254(116)$ & $2634(143)$ & $2545(126) \star$ & $3215(172)^{\star \star}$ \\
Ulcer healing agents & $1504(101)$ & $1614(98)$ & $1703(97)^{\star}$ & $2124(128)^{\star \star}$ \\
\hline
\end{tabular}

${ }^{\star} \mathrm{p}<0.01$ compared with control group at baseline.

${ }_{\star \star} \mathrm{p}<0.0001$ compared with study group at baseline.

the number of items prescribed, but the prescribing costs in the study group increased $22 \%$, from a mean of $£ 2634$ to $£ 3215$ per GP $(\mathrm{p}<0.0001)$, almost entirely due to the increased costs of ulcer-healing drugs, from $£ 1614$ to $£ 2124$ per GP $(\mathrm{p}<0.001)$, an increase of $32 \%$. Prescribing costs (for both upper gastrointestinal and ulcer-healing drugs also increased significantly (by $13 \%$ ) in the control group (table 4).

Not surprisingly, GPs who entered the study as high prescribers of ulcer-healing drugs showed a smaller rise in their prescribing costs than those whose initial prescribing costs were low. Additionally, although numbers were small, there was some evidence that participation in developing the guidelines at the consensus meetings was associated with a greater change in prescribing behaviour.

\section{Discussion}

This study showed that management guidelines for a common medical condition, in this case dyspepsia, can be developed by consensus between GPs and hospital specialists, while it raised serious questions about implementation and changes in clinical behaviour. Using published information, GPs, physicians, surgeons, and radiologists were able to agree on a set of management guidelines. Although participation in this process was clearly not regarded as a priority by many of those invited to the consensus meetings, the process of developing the guidelines was amicable and constructive, with each group learning from the others. The recommendations agreed in this research project were the result of a series of six evening meetings each lasting about two hours, and they now form the basis for dyspepsia management protocols in various other sites. This process could form a model for developing district guidelines for other important conditions. Disorders with greater implications for mortality, surveillance, or structured care in general practice might prove more popular topics for developments of this kind.
We set out to determine whether the introduction of these guidelines had any measurable effect on GPs' referrals to outpatient departments, use of investigations, and prescribing for gastrointestinal symptoms. An unexpected finding was an overall fall in the total number of outpatient referrals for gastrointestinal problems in the face of a general increase in overall referral rates to medical and surgical outpatient departments. We do not have a ready explanation, but it may well be related to patient, general practice, or hospital factors that were not measured as part of this research.

There was no evidence that GPs were making better use of the investigations: just as many patients aged under 50 were referred, the proportion of examinations with normal results was unchanged, and identification rates of major upper gastrointestinal lesions did not increase. These results might have been expected, as major changes in referral and investigation behaviour would imply substantial changes in beliefs and, more importantly, habits; it is possibly overoptimistic to believe that merely circulating documents to GPs will produce such changes. We were asking general practitioners to make two changes in their behaviour in relation to these investigations: to modify their selection of patients for investigation and to review the choice of investigations. Given the longstanding controversy about the relative merits of endoscopy and radiology, the wide range of clinical experience of the GPs in the study, and the contrast between open access radiology and consultant referred endoscopy, it would probably have been unrealistic to have expected major changes in the use of these investigations. Possibly the lack of effect of the guidelines reflected existing good clinical practice in the study practices before their introduction; against this view is the investigation rate in young dyspeptic patients and the wide variations in prescribing and referral behaviour within the practices, which are likely to reflect variations in the quality of practice.

In relation to prescribing, however, a "brakes off" recommendation was contained in the guidelines, for prescribing of ulcerhealing drugs before endoscopy. Low prescribers clearly found the guidelines' endorsement of empirical therapy before investigation appealing, and this behavioural change occurred with relative ease, although prescribing $\mathrm{H}_{2}$-antagonist was not accompanied by a fall in investigation rates.

Studies published subsequently comparing early endoscopy and empirical ulcer-healing therapy suggest that investigation rather than "blind" therapy is most cost effective, ${ }^{14} 15$ although the debate is likely to continue. One interpretation of the implications of variations in the use of drugs and investigations follows from this - namely, that GPs who are high (empirical) prescribers and low (late) investigators may be providing care which is as appropriate and clinically effective as low ("rational") prescribers and high (early) 
investigators. The expectation of a shift towards the mean in all practices might represent an oversimplified view of good practice.

The British Society of Gastroenterology's document on the provision of endoscopic facilities in district general hospitals ${ }^{16}$ incorporates some of these Southampton guidelines; other individuals and groups have requested material for consideration and modification to suit their own local and individual requirements. This type of material may not be formally "published" and referenced but it would be helpful if it were collated and made available to groups involved in audit and those requiring guidelines for good practice. Regional health authorities, the Department of Health, the specialist societies, and the royal colleges are all involved in audit and in producing guidelines; it may be appropriate for them to ensure that this information is made accessible. However, Farmer emphasised some problems in GPs' acceptance of "off the peg" guidelines prepared by organisations "with an interest in influencing the care offered to patients with chronic diseases."17 $\mathrm{He}$ underlined the importance of taking into account not only the outcomes for patients but the views of patients themselves in formulating health policies. Eddy suggested that the status of policies should be made clear by classifying them as standards, guidelines, or options, depending largely on the strength of the supporting scientific evidence and the potential for choices between strategies to be made by clinicians and patients. ${ }^{18}$ This reminder of the central position of the patient as consumer of health care is timely, yet the viewpoint which it reflects is entirely compatible with the process for generating guidelines, which begins with a joint review of the clinical evidence by specialists and generalists and ends with the adaptation of guidelines for use according to local conditions and requirements.

As well as underlining the difficulties of translating guidelines into action, this study also indicates some of the problems in determining their outcome. Investigation, referral, and prescribing rates are only proxy measures of the quality of care, yet longer term, patient-centred outcome measures will add to the cost and complexity of evaluation.

This study emphasises the gap between producing documentary information - in this case guidelines, although research publications can be regarded in the same way - and implementation and behavioural change. ${ }^{19}$ The key issues of dissemination and implementation are now being addressed centrally, within the Department of Health ${ }^{20}$ and through the Cochrane Centre, established as part of the NHS research and development programme and with the assembly and dissemination of a register of controlled trials as one of its key functions. ${ }^{21}$

This study was supported by the Primary Health Care Development Fund. We thank Smith Kline Beecham for further funding, our colleagues in general practice and the Southampton hospitals who participated in the project, and Jenny Bartholomew and Clare Jenkins for their help with data analysis.

1 Donabedian A. Evaluating the quality of medical care. Millbank $Q$ 1966;44:166-206.

2 Smith A. In search of consensus. BMF 1991;302:800.

3 Martin AR, Wolf MA, Thibodeau LA, Dean V, Braunwald Martin AR, Wolf MA, Thibodeau LA, Dean V, Braunwald
E. A trial of two strategies to modify the test - ordering E. A trial of two strategies to modify the test - ordering
behaviour of medical residents. $N$ Engl $\mathcal{J}$ Med behaviour of medi

4 Harris C, Jarman B, Woodman E, et al. Prescribing: a suitable case for treatment. London: Royal College of General Practitioners, 1984. (Occasional paper 24.)

5 Kosecoff J, Kanouse DE, Rogers WH, McClosket L, Winslow CM, Brook RH. Effect of the National Institutes of Health consensus development program on physician practice. $\mathcal{F} A M A$ 1987;258:2708-13.

6 Russell IT, Grimshaw J. The effectiveness of referral guidelines: a review of methods and findings of published evaluations. In: Roland $\mathrm{M}$, Coulter $\mathrm{A}$, eds. Hospital referrals. Oxford: Oxford University Press,
rentalions. In: Roland referrals. Ox- $179-221$.

7 Jones R. Dyspeptic symptoms in the community. Gut 1989;30:893-8.

8 Heatley RV, Rathbone BJ. Dyspepsia: a dilemma for doctors? Lancet 1987;ii:779-82.

9 Williams B, Luckas M, Ellingham JHM, et al. Do young patients with dyspepsia need investigation? Lancet 1988;ii: $1349-51$

10 Jones RH, Lydeard SE, Hobbs FDR, Kenkre JE, Williams EI, Jones SJ, et al. Dyspepsia in England and Scotland. Gut 1990;31:401-5.

11 Jones RH, Lydeard SE. Prevalence of symptoms of dyspepsia in the community. BMF 1989;298:30-2.

12 Colin-Jones DG. Management of dyspepsia: a report of a working party. Lancet 1988;i:576-9.

13 British National Formulary. London: BMA and Royal Pharmaceutical Society of Great Britain, 1992.

14 Goulston KJ, Dent OF, Mant A, Logan J, Ngu M. Use of $\mathrm{H}_{2}$-receptor antagonists in patients with dyspepsia: a cost $\mathrm{H}_{2}$-receptor antagonists in patients with
comparison. Med f A ust 1991;158:20-5.

15 Nyren O, Lindberg G, Lindstrom E, Marke L-A, Seensalu R. Economic costs of functional dyspepsia. R. Economic costs of functic

16 Clinical Services Committee, British Society of Gastroenterology. Provision of gastrointestinal endoscopy and related services for a district general hospital: report of a working party. London: BSG, 1990.

17 Farmer A. Setting up consensus standards for the care of patients in general practice. $\mathrm{Br} \mathcal{F}$ Gen Pract 1991;41:135-6.

18 Eddy DM. Designing a practice policy. Standards, guidelines, and options. $\mathcal{F} A M A$ 1990;263:3077-84.

19 Haines A, Feder G. Guidance on guidelines. $B M F$ 1992;305:785-6.

20 Department of Health. Research for health. London: DOH, 1993.

21 Chalmers I, Dickersin K, Chalmers TC. Getting to grips with Archie Cochrane's agenda. BMf 1992;305:786-7. 